\title{
Kajian Minat Wisatawan Di Museum Memorial Jenderal Besar HM. Soeharto Di Kabupaten Bantul
}

\author{
Ajie Wicaksono \\ Akademi Pariwisata STIPARY Yogyakarta \\ E-mail : jiewic90@gmail.com
}

\begin{abstract}
This study aimed to examine the interest of tourists at the HM General Memorial Museum. Suharto in Bantul Regency. This study employed descriptive qualitativemethodand the data were collected through interview, observation, literature studies, and documentation. Interview wascarried outwith managers and visitors (public peopleand students). The data analyzed using Miles Hubberman's qualitative descriptive analysis coveringdata reduction, data presentation, and drawing conclusion. The results showed that the interest of tourists at the HM General Memorial Museum Soeharto was quite high. In addition to that, the interest of the vast majority ofthe students who visited the HM General Memorial Museum. Soeharto was to conduct a study tour and find out the life history of the Great General HM. Suharto, while the personal interest of the university studentswas to find out information about the life history of the Great General HM. Suharto and gather with fellow students to just discuss and enjoy wifi facilities. The interest of the public peoplewasto reminisceaboutthe late Great General HM. Suharto. Visitors werealso interested coming to the HM General Memorial Museum. Suharto for recreation and gathering with friends and family.Moreover, they enjoyed adequate facilities available, of museum's collections which were diverse and packaged in a modern way, as well as the historical elements related to Soeharto's life that invited visitors to be curious while providing education for visitors. Visitors also showed social interest when they visited to the HM General Memorial Museum. Soeharto either gathering with family and friends or participating in various community activities such as commemorating national holidays and participating in competitions, gymnastics and others.
\end{abstract}

Keywords: Soeharto museum, tourism, tourist interest

Abstract - Penelitian ini bertujuan untuk mengkaji minat wisatawan di Museum Memorial Jenderal Besar HM. Soeharto di Kabupaten Bantul. Metode dalam penelitian ini yaitu deskriptif kualitatif dengan pengumpulan data melalui wawancara, observasi, studi pustaka, dan dokumentasi. Wawancara dilakukan kepada pengelola dan pengunjung (umum, pelajar, dan mahasiswa). Analisis data menggunakan analisis deskriptif kualitatif Miles Hubberman yaitu reduksi data, penyajian data, dan penarikan kesimpulan. Hasil penelitian menunjukkan bahwa minat wisatawan di Museum Memorial Jenderal Besar HM. Soeharto cukup tinggi, Minat pribadi pelajar yang mengunjungi Museum Memorial Jenderal Besar HM. Soeharto umumnya adalah untuk melakukan study tour serta mengetahui sejarah kehidupan Jenderal Besar HM. Soeharto, sedangkan minat pribadi mahasiswa adalah untuk mengetahui informasi tentang sejarah kehidupan Jenderal Besar HM. Soeharto serta berkumpul dengan rekan-rekan sesama mahasiswa untuk berdiskusi maupun menikmati fasilitas wifi. Minat pribadi masyarakat umum adalah bernostalgia dengan mendiang Jenderal Besar HM. Soeharto. Pengunjung juga berminat datang ke Museum Memorial Jenderal Besar HM. Soeharto untuk berekreasi dan berkumpul bersama teman dan keluarga sambil memanfaatkan beragam fasilitas yang cukup memadai. Adanya koleksi museum yang beragam dan dikemas secara modern, serta adanya unsur historis terkait kehidupan Jenderal Besar HM. Soeharto yang mengundang rasa penasaran pengunjung sekaligus memberikan edukasi bagi pengunjung. Pengunjung juga menunjukkan minat sosial ketika datang ke Museum Memorial Jenderal Besar HM. Soeharto baik sekedar berkumpul dengan keluarga dan teman maupun mengikuti berbagai kegiatan komunitas seperti memperingati hari besar nasional maupun mengikuti kegiatan lomba, senam dan lain-lain.

Kata kunci: museum soeharto, pariwisata, minat wisatawan

\subsection{Latar Belakang}

Pariwisata di Daerah Istimewa

Yogyakarta (DIY) menjadi menjadi pilihan sebagian besar masyarakat. Hal tersebut dilihat dari jumlah kunjungan wisatawan yang terus meningkat dari tahun ke tahun. Berdasarkan data dari Buku Statistik
Kepariwisataan selama 3 tahun terakhir yaitu 2015-2017, jumlah wisatawan terus menunjukkan kenaikan baik wisatawan domestik maupun mancanegara. Data kunjungan secara rinci dapat dilihat pada tabel berikut: 
Tabel 1. Data Kunjungan Wisatawan DIY 2015-2017

\begin{tabular}{|l|r|r|r|r|r|r|}
\hline \multirow{2}{*}{ Tahun } & \multicolumn{3}{|c|}{ Wisatawan domestik (orang) } & \multicolumn{3}{c|}{ Wisatawan mancanegara (orang) } \\
\cline { 2 - 7 } & \multicolumn{3}{|c|}{ Tahun } & \multicolumn{1}{c|}{ Tahun } \\
\cline { 2 - 7 } & $\mathbf{2 0 1 5}$ & $\mathbf{2 0 1 6}$ & $\mathbf{2 0 1 7}$ & $\mathbf{2 0 1 5}$ & \multicolumn{1}{c|}{$\mathbf{2 0 1 6}$} & \multicolumn{1}{c|}{$\mathbf{2 0 1 7}$} \\
\hline Kota Yogyakarta & 5.388 .352 & 5.271 .471 & 5.049 .608 & 232.913 & 249.481 & 297.695 \\
\hline Kab. Sleman & 4.695 .740 & 5.439 .165 & 6.552 .487 & 255.194 & 246.136 & 262.071 \\
\hline Kab. Bantul & 4.763 .614 & 5.400 .260 & 9.130 .657 & 0 & 5.540 & 10.493 \\
\hline Kab.Gunung Kidul & 2.642 .759 & 3.476 .008 & 3.225 .929 & 5.319 & 3.882 & 21.067 \\
\hline Kab.Kulon Progo & 1.289 .672 & 1.346 .894 & 1.390 .331 & 23 & 6.506 & 10.455 \\
\hline \multicolumn{1}{|c|}{ Jumlah } & 19.266 .233 & 21.445 .343 & 25.950 .793 & 493.449 & 511.545 & 601.781 \\
\hline
\end{tabular}

Sumber: Buku Statistik Kepariwisataan DI Yogyakarta (https://visitingjogja.com)

Berdasarkan data di atas, Kabupaten Bantul merupakan tempat yang paling banyak dikunjungi terutama wisatawan nusantara/domestik. Berbagai pilihan tempat yang dikunjungi di kabupaten Bantul antara lain pantai, makam raja, kawasan cagar budaya, desa wisata, gua, kebun buah, dan sebagainya. Bahkan museum menjadi salah satu lokasi yang menjadi tujuan kunjungan.

Museum menjadi salah satu objek wisata yang terus dikembangkan oleh pemerintah. Hal ini sebagai bentuk perhatian pemerintah terhadap pelestarian sejarah dan warisan budaya yang ada di Indonesia untuk dikenalkan dari generasi ke generasi. Dean (2013: 61) menyatakan bahwa museum merupakan tempat untuk menyimpan beragam warisan budaya dan berbagai bukti kekayaan alam yang bernilai tinggi, dimana tempat tersebut dapat dikunjungi orang untuk melakukan penelitian untuk inspirasi, pembelajaran, dan kesenangan.

Salah satu museum di kabupaten Bantul adalah Museum Memorial Jenderal Besar HM. Soeharto. Museum ini terletak di Dusun Kemusuk, Desa Argomulyo, Kecamatan Sedayu, Kabupaten Bantul, DIY. Tempat ini menjadi salah satu obyek wisata yang berisi tentang sejarah Jenderal Besar HM. Soeharto semasa menjalankan tugas pemerintahan sebagai presiden kedua $\mathrm{RI}$ selama 32 tahun yaitu periode tahun 1966-1998. Museum ini diresmikan bertepatan dengan tanggal kelahiran Jenderal Besar HM. Soeharto yaitu 8 Juni, pada tahun 2013. Museum ini dibangun dan diresmikan oleh Bapak H. Probosutedjo (adik) dan Siti Hardianti Rukmana (putri pertama) di atas lahan seluas 3.620 meter persegi.

Sebagai pemimpin $\mathrm{RI}$ dengan masa pemerintahan terlama, tentu banyak hal yang bisa digali dari berbagai peninggalan Jenderal Besar HM. Soeharto selama memimpin. Wisatawan yang berkunjung pun tidak sedikit. Berdasarkan data dari Buku Statistik Kepariwisataan DI Yogyakarta, jumlah kunjungan pada tahun 2015 sebanyak 250.050 orang, dan menurun pada tahun 2016 sebanyak 206.563. Kunjungan tahun 2017 pun menurun menjadi 183.735 orang. Berdasarkan hal ini maka menarik untuk dikaji mengenai minat wisatawan dalam kunjungannya ke Museum Memorial Jenderal Besar HM. Soeharto.

\subsection{Kajian Pustaka}

\subsubsection{Teori Pariwisata}

Menurut Kodhyat (2013: 78), pariwisata adalah perjalanan dari suatu tempat ke tempat lain, bersifat sementara, dilakukan perorangan atau kelompok, sebagai usaha mencari keseimbangan atau keserasian dan kebahagiaan dengan lingkungan dalam dimensi sosial, budaya, alam dan ilmu. Suwantoro (2011: 47) mengemukakan bahwa pariwisata didefinisikan sebagai bentuk, suatu proses kepergian sementara seseorang menuju tempat lain di luar tempat tinggalnya. Dorongan kepergiannya karena berbagai kepentingan diantaranya kepentingan ekonomi, sosial, budaya, politik, agama, kesehatan maupun kepentingan lainnya. Burkart dan Medlik (2012: 96) menjelaskan pariwisata sebagai suatu trasformasi orang untuk sementara dan dalam waktu jangka pendek dengan tujuan di luar tempat di mana mereka biasanya hidup dan bekerja, serta kegiatan-kegiatan mereka selama tinggal.

Menurut Undang-Undang No. 10 Tahun 2009 Pasal 1 butir 3, pariwisata adalah berbagai macam kegiatan wisata dan didukung berbagai fasilitas serta layanan yang disediakan oleh masyarakat, pengusaha, pemerintah dan pemerintah daerah. Berdasarkan beberapa definisi tersebut maka disimpulkan bahwa pariwisata merupakan aktifitas manusia untuk sementara waktu yang dilakukan secara sadar dari satu tempat ke tempat lain dengan tujuan untuk bersenangsenang dan bukan mencari nafkah dengan berbagai kegiatan pariwisata.

\subsubsection{Museum sebagai Daya Tarik Pariwisata}

Museum adalah lembaga, tempat penyimpanan, perawatan, pengamanan, dan pemanfaatan benda-benda bukti materiil hasil budaya manusia serta alam dan lingkungannya guna menunjang upaya 
perlindungan dan pelestarian kekayaan budaya bangsa. Museum adalah tempat untuk mengumpulkan, menyimpan, merawat melestarikan, mengkaji, mengkomunikasikan bukti material hasil budaya manusia, alam dan lingkungannya (Sutaarga, 2012: 1).

Maryani (2012: 18) mengemukakan bahwa produk wisata budaya, termasuk museum terdiri dari atraksi dan benda peninggalannya. Pengelompokan museum berdasarkan koleksinya sebagai berikut:

1. Archeological, historical and culture sites, yang termasuk dalam situs budaya, sejarah dan arkelogi adalah monumen nasional dan budaya, bangunan peribadatan bersejarah (misalnya masjid, gereja, kuil), bangunan (gedung) bersejarah, daerah dan kota berbagai tempat penyelenggaraan event bersejarah lain.

2. Distinctive culture patterns, pola kebudayaan, tradisi dan gaya hidupnya tidak biasa (berbeda dengan yang dimiliki oleh para wisatawan)

3. Art and handicraft, yang termasuk di dalamnya adalah tarian, musik, drama, seni melukis, memahat. Karya tersebut dapat menjadi suatu atraksi yang sangat menarik bagi wisatawan terutama jika dikemas dengan baik.

4. Interesting economic activities. Salah satu jenis atraksi wisata yang sukses adalah observasi, deskripsi, dan terkadang demonstrasi dari suatu aktivitas perekonomian yang menarik seperti pasar tradisional.

5. Interesting urban areas. Area urban berbeda dengan area pedesaan, area perkotaan dengan variasi gaya arsitektur, bangunan-bangunan dan daerah-daerah bersejarah. Tempat ini merupakan suatu atraksi bagi wisatawan yang menikmati pemandangan perkotaan dan karakteristik kota tersebut.

6. Museum and other culture fasilities, misalnya museum bersejarah dan fasilitas kebudayaan lainnya seperti barang antik dan galeri.

7. Cultural festivals, beberapa tipe festival kebudayaan yang terkait dengan tradisi lokal dan kesenian dapat menjadi atraksi yang utama.

Dalam industri pariwisata, museum menjadi objek dan daya tarik wisata. Dalam perspektif pariwisata, museum tidak hanya berfungsi sebagai objek penelitian dan pendidikan, namun juga berperan untuk tujuan dan penyelenggara rekreasi. Oleh sebab itu, sudah sepantasnya museum dikelola demi memenuhi 3 unsur daya tarik museum. Seperti dikemukan Boniface \& Fowler (2011:102) bahwa 3 unsur tersebut meliputi enjoyment (unsur kenikmatan), entertainment (unsur hiburan), dan education (unsur pendidikan).

Museum digunakan sebagai tempat untuk melakukan kegiatan hiburan. Pengunjung dapat melakukan aktivitas untuk menikmati koleksi melalui pameran sambil memperoleh ilmu pengetahuan tentang koleksi. Hiburan dan pendidikan muncul sebagai hubungan simbiotik yang unik di dalam museum dengan tujuan menarik minat dan mendidik pengunjung sehingga dapat memenuhi kebutuhan untuk bersenang-senang dan menghibur. Museum juga dapat dijadikan sebagai daya tarik bagi wisatawan yang ingin memperoleh pengetahuan melalui koleksi dan tata pameran dengan nuansa yang rekreatif (Boniface \& Fowler, 2011:103).

\subsubsection{Teori Minat Kunjungan}

Minat merupakan suatu ketertarikan individu terhadap satu obyek tertentu yang membuat individu itu sendiri merasa senang dengan obyek tersebut. Mappier (2013: 62) menjelaskan bahwa minat adalah suatu perangkat mental yang terdiri dari campurancampuran perasaan, harapan, pendidikan, rasa takut atau kecenderungankecenderungan lain yang menggerakan individu kepada suatu pilihan tertentu.

Minat kunjungan adalah kecenderungan seseorang untuk mendatangi objek atau suatu kegiatan yang digemari yang disertai dengan perasaan senang, adanya perhatian, dan keaktifan melakukan sesuatu. Menurut Marpaung (2012: 89), apabila perubahan minat fisik dan psikologis pada seseorang ini berkurang, maka perubahan minat juga akan berkurang. Meskipun variasi minat pada orang dewasa sangat luas, beberapa jenis minat tertentu dapat dianggap sebagai ciri orang dewasa. Jenis ini dapat dibagi dalam tiga kategori, yaitu :

1. Minat Pribadi

Minat pribadi selalu menyangkut seseorang. Minat pribadi yang kuat dapat menyebabkan seseorang bersifat egosentris. Namun dengan bertambahnya tugas dan tanggung jawab maka minat egosentris biasanya sedikit demi sedikit berkurang dan minat sosial mulai berkembang. Minat pribadi diartikan sebagai karakteristik kepribadian seseorang yang relatif stabil, cenderung menetap pada diri seseorang. Minat pribadi biasanya dapat langsung membawa seseorang pada beberapa aktivitas atau topik yang spesifik. Minat pribadi dapat 
dilihat ketika seseorang menjadikan sebuah aktivitas atau topik sebagai pilihan untuk hal yang pasti, secara umum menyukai topik atau aktivitas tersebut, menimbulkan kesenangan pribadi serta topik atau aktivitas yang dijalani memiliki arti penting bagi seseorang.

2. Minat Rekreasi

Minat rekreasi adalah minat untuk bersenang-senang atau untuk menghibur diri sendiri, seperti mengunjungi tempattempat wisata, entertainment atau bahkan berbincang-bincang dengan orang lain. Faktor yang membuat seseorang melakukan rekreasi adalah adanya waktu yang dimiliki seseorang sehingga dapat menggunakan waktu luangnya tersebut untuk berekreasi ke museum umtuk menikmati dan melihat-lihat koleksi museum. Adanya minat rekreasi membuat seseorang menggunakan tempat wisata sebagai tempat yang dipilih untuk relaksasi meghilangkan penat ataupun mencari hiburan untuk mencari kesenangan.

3. Minat Sosial

Masa dewasa sebagaimana ditekankan oleh Erickson, merupakan masa krisis keterasingan. Dalam masa ini pria maupun wanita sering merasa kesepian (baik yang berumah tangga maupun yang masih lajang), sehingga mereka perlu untuk melakukan interaksi atau hubungan dengan orang lain untuk menghibur diri mereka sendiri.

\subsection{Metode Penelitian}

Penelitian ini merupakan penelitian deskriptif kualitatif. Penelitian dilakukan di Museum Memorial Jendral Besar HM. Soeharto, di Dusun Kemusuk, Desa Argomulyo, Kecamatan Sedayu, Kabupaten Bantul, DIY. Pengumpulan data dilakukan dengan wawancara, observasi, studi pustaka, dan dokumentasi. Wawancara dilakukan kepada informan yang memahami tentang seluk beluk Museum Memorial Jendral Besar HM. Soeharto yaitu pengelola museum. Informan juga dipilih untuk mendapatkan data mengenai minat pengunjung sehingga wawancara dilakukan terhadap pengunjung yang dikategorikan kalangan umum, pelajar, dan mahasiswa. Jenis data dalam penelitian ini yaitu data primer yang merupakan hasil wawancara dan data sekunder yang diperoleh dari observasi (pengamatan), dokumentasi (foto museum, koleksi, dan sebagainya), serta studi pustaka (jurnal penelitian dan buku-buku yang berkaitan dengan kajian ini). Analisis data menggunakan analisis kualitatif Miles
Hubberman yang meliputi reduksi data, penyajian data, dan kesimpulan.

\subsection{Hasil Penelitian Dan Pembahasan 4.1.1. Deskripsi Objek Penelitian}

Museum Memorial HM. Soeharto dibangun oleh $\mathrm{H}$. Probosutedjo, adik Jenderal Besar H.M Soeharto untuk mengenang jasa dan pengabdian, serta penghargaan terhadap prestasi dan keberhasilan yang telah dilakukan HM. Soeharto. Museum ini diresmikan pada 8 Juni 2013 di Dusun Kemusuk, Desa Argomulyo, Kecamatan Sedayu, Bantul, DIY di atas lahan seluas 3.620 meter persegi.

Visi Museum Memorial Jenderal Besar H.M. Soeharto adalah: "Museum sebagai wahana pendidikan sejarah bangsa untuk mengenang jasa dan pengabdian, serta penghargaan terhadap prestasi dan keberhasilan Jenderal Besar H.M. Soeharto yang telah menghantarkan Bangsa Indonesia menjadi bangsa yang bermartabat, maju dan sejahtera". Misi Museum Memorial Jenderal Besar H.M. Soeharto sebagai berikut:

1. Menjadikan museum sebagai bagian dari edukasi pendidikan sejarah anak bangsa, untuk mengenang kejuangan, prestasi dan pengabdian yang di berikan oleh Alm. Bapak Presiden Republik Indonesia Ke-2, Jenderal Besar H.M. Soeharto.

2. Menjadikan museum sebagai tempat untuk meningkatkan dan memantabkan jiwa nasionalisme dan wawasan kebangsaan bagi masyarakat umum dan pemuda, pelajar sebagai generasi penerus bangsa.

3. Menjadikan museum sebagai sumber inspirasi bagi generasi penerus agar nilainilai kejuangan yang terkandung didalamnya menjadi pelajaran berharga untuk menyongsong masa depan bangsa.

Museum Memorial Jenderal Besar H.M. Soeharto buka setiap hari mulai pukul 08.3016.30 WIB. Museum yang dibangun di atas lahan keluarga seluas $3.620 \mathrm{~m}^{2}$, terdiri atas:

1. Bangunan Pendopo Utama memiliki luas $600 \mathrm{~m}^{2}$. Di depan bangunan ini terdapat halaman seluas $400 \mathrm{~m}^{2}$ yang digunakan untuk kegiatan upacara, senam bersama dan kegiatan permainan anak-anak. Pendopo Utama adalah pusat untuk memberikan informasi, edukasi tentang museum, sejarah Jenderal Besar H.M. Soeharto sebagai Presiden Rl ke- 2, memberi motivasi tentang wawasan kebangsaan, nasionalisme dan sarana hiburan serta untuk memutar film sejarah bangsa. Di dalam Pendopo Utama terdapat koleksi dan sarana pendukung edukasi antara lain: patung berbahan perunggu 
dengan tinggi 1,5 meter Jenderal Besar H.M. Soeharto dalam pose hormat, seperangkat gamelan jawa (pelok dan slendro), televisi LED 80" untuk memutar dokumentasi sejarah, dan televisi LED 60" untuk menayangkan dokumen foto-foto pengunjung dalam bentuk slide berjalan.

2. Patung Jenderal Besar H.M. Soeharto dengan tinggi 2,5 meter. Di bagian depan pendopo utama, tepatnya di tengah gerbang pintu masuk atau pintu utama berdiri tegak patung Jenderal Besar H.M. Soeharto menyambut kedatangan pengunjung. Patung ini adalah simbol utama dari Museum.

3. Patung anak kecil sedang menggembala kerbau di atas kolam ikan, terdapat di pojok sebelah kiri gerbang pintu masuk. Patung ini menggambarkan masa-masa kecil Soeharto saat hidup di pedesaan, di desa Kemusuk.

4. Relief tentang kepemimpinan dalam falsafah Jawa dan patung Jenderal Besar H.M. Soeharto sedang melaksanakan sholat. Kepemimpinan dalam falsafah Jawa ada tiga kata yang mendasari yaitu: $\mathrm{Sa}-\mathrm{Sa}$ Sa yang artinya seorang pemimpin harus selalu ("Sa" pertama) Sabar atine, artinya hatinya selalu dalam keadaan sabar, ("Sa" kedua) Saleh pikolahe, artinya selalu taat beribadah dalam beragama dan ("Sa" ketiga), Sareh tumindake, artinya seorang pemimpin harus selalu bijaksana dalam bersikap bertindak dalam memerintah negeri ini.

5. Rumah Notosudiro, yaitu eyang buyut Jenderal Besar H.M. Soeharto dengan luas $475 \mathrm{~m}^{2}$, digunakan untuk rumah tinggal keluarga besar Alm. Bapak H.M. Soeharto ketika pulang ke Yogyakarta. Di samping itu rumah tersebut digunakan untuk menerima tamu VIP dan untuk kegiatan kantor.

6. Rumah Atmosudiro, eyang Jenderal Besar H.M. Soeharto dengan luas $250 \mathrm{~m}^{2}$. Rumah ini digunakan sebagai Diorama Utama yang menceritakan sejarah panjang perjalanan hidup Presiden RI ke-2 Bapak Jenderal Besar H.M. Soeharto. Diorama dibagia menjadi 5 (lima) selasar yaitu Selasar A,B,C,D dan E. Selasar-selasar tersebut sebagai berikut:

Tabel 2. Selasar Rumah Atmosudiro

\begin{tabular}{|c|c|c|}
\hline No & Selasar & Isi Selasar \\
\hline 1 & $\begin{array}{l}\text { Selasar A: } \\
\text { Pengantar } \\
\text { Memorial }\end{array}$ & $\begin{array}{l}\text { a. Hologram door figure } \\
\text { (gunungan dan siluet } \\
\text { wajah Jenderal Besar } \\
\text { HM. Soeharto) dengan } \\
\text { automatic door } \\
\text { b. Silde film animasi sawah }\end{array}$ \\
\hline
\end{tabular}

\begin{tabular}{|c|c|c|}
\hline & & $\begin{array}{l}\text { dengan teknologi } \\
\text { proyektor } \\
\text { c. Treatment dinding Black } \\
\text { Out } \\
\text { d. Interactive Floor } \\
\text { e. Art Acrylic nama-nama } \\
\text { selasar. }\end{array}$ \\
\hline 2 & $\begin{array}{l}\text { Selasar B: } \\
\text { Serangan } \\
\text { Umum }\end{array}$ & 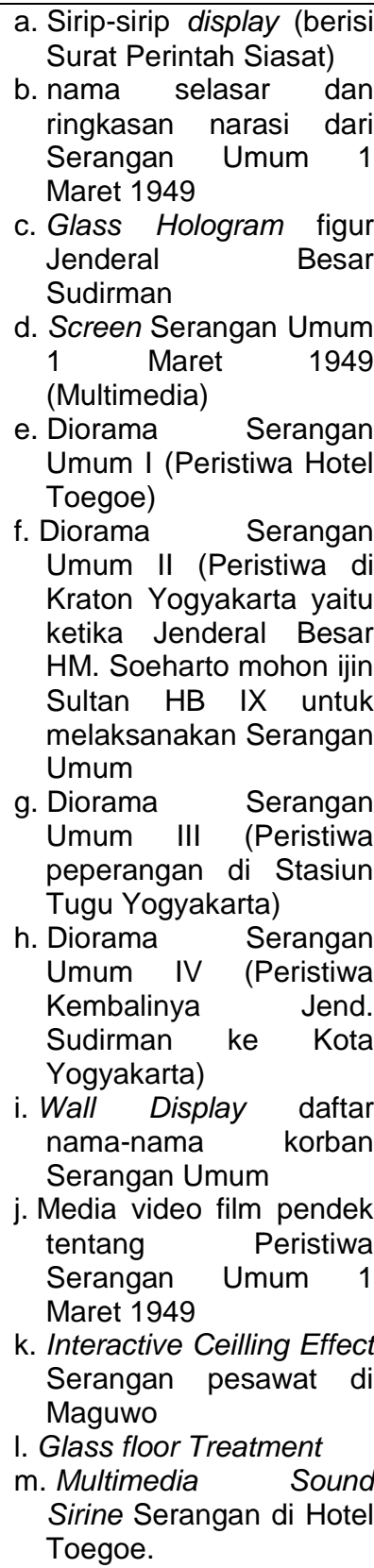 \\
\hline 3 & $\begin{array}{l}\text { Selasar } \quad \text { C: } \\
\text { Operasi } \\
\text { Trikora }\end{array}$ & $\begin{array}{ll}\text { a. } \text { Multimedia Choptic } \\
\text { Peristiwa Trikora } \\
\text { b. Wall Display } & \text { Peristiwa } \\
\text { Trikora } & \\
\text { c. Diorama } & \text { Operasi } \\
\text { Mandala I } & \\
\text { d. Diorama } & \text { Operasi } \\
\text { Mandala II } & \\
\text { e. Art Glass Armada } & \text { Operasi Mandala } \\
\text { f. Art Glass Komodor Yos }\end{array}$ \\
\hline
\end{tabular}

ISSN : 2087-0086 (print), 2655-5433 (online) 


\begin{tabular}{|c|c|c|}
\hline & & $\begin{array}{l}\text { Sudarso } \\
\text { g. Wall Display Figur } \\
\text { Mayor Jend. Soeharto } \\
\text { h. Art Glass Armada } \\
\text { Operasi Mandala } \\
\text { i. Wall Display UNTEA } \\
\text { Irian Barat } \\
\text { j. Multimedia Screen TV } \\
\text { Perpera Irian Barat } \\
\text { k. Figure Picture HM. } \\
\text { Soeharto I } \\
\text { I. Art Display Gunungan } \\
\text { m. Figure Picture HM. } \\
\text { Soeharto II } \\
\text { n. Display Peta Indonesia } \\
\text { Integrasi Irian Jaya. }\end{array}$ \\
\hline 4 & $\begin{array}{l}\text { Selasar D: } \\
\text { Pemberonta } \\
\text { kan G } 30 \\
\text { S/PKI dan } \\
\text { Kesaktian } \\
\text { Pancasila }\end{array}$ & $\begin{array}{l}\text { a. Display nama Selasar } \\
\text { Kesaktian Pancasila } \\
\text { b. Display Penumpasan G } \\
\text { 30 S/PKI } \\
\text { c. Display Peristiwa G } 30 \\
\text { S/PKI kronologi } \\
\text { peristiwa (Lubang } \\
\text { Buaya dan Hologram } \\
\text { Garuda Pancasila) } \\
\text { d. Figur Pangkostrad Lima } \\
\text { Jaya MayJend. } \\
\text { Soeharto G } \\
\text { e. Display Pembubaran G } \\
\text { 30 S/PKI } \\
\text { f. Display Memo Komando } \\
\text { Operasi Mandala } \\
\text { kepada Presiden } \\
\text { g. Display Pengkianatan G } \\
\text { 30 S/PKI (Panel Touch } \\
\text { Screen Ringkasan } \\
\text { Narasi Peristiwa Sekitar } \\
\text { Pemberontakan PKI) } \\
\text { h. Floating Glass Diorama } \\
\text { Peristiwa G } 30 \text { S /PKI } \\
\text { i. Display Surat Perintah 1 } \\
\text { Maret 1966 mengenai } \\
\text { Pembubaran PKI } \\
\text { j. Siluet Figur Jenderal } \\
\text { Besar HM. Soeharto } \\
\text { k. Art Acrylic Laser Figur } \\
\text { Pahlawan yang gugur di } \\
\text { Peristiwa G } 30 \text { S/PKI. }\end{array}$ \\
\hline 5 & $\begin{array}{l}\text { Selasar E: } \\
\text { Masa } \\
\text { Pembangun } \\
\text { an }\end{array}$ & $\begin{array}{l}\text { a. Interactive Mouch } \\
\text { Screen Mulimedia } \\
\text { Tentang Pembangunan } \\
\text { b. Multimedia Masa } \\
\text { Pembangunan tayangan } \\
\text { film dokumenter selama } \\
\text { Kepemimpinan Jenderal } \\
\text { Besar HM. Soeharto } \\
\text { c. Mozaik Acrylic Masa } \\
\text { Pembangunan } \\
\text { d. Display Pengunduran } \\
\text { Diri Presiden RI ke-2 } \\
\text { Jenderal Besar HM. } \\
\text { Soeharto Mar } \\
\text { e. Acrylic Display Masa } \\
\text { Pembangunan Repelita } \\
\text { f. Multimedia Touch }\end{array}$ \\
\hline
\end{tabular}

\begin{tabular}{|c|c|c|}
\hline & & $\begin{array}{l}\text { Screen Pidato Presiden } \\
\text { Soeharto lengser dan } \\
\text { Upacara Pemakaman } \\
\text { pidato Presiden Susilo } \\
\text { Bambang Yudoyono } \\
\text { pada saat Pemakaman } \\
\text { Jenderal Besar HM. } \\
\text { Soeharto. }\end{array}$ \\
\hline
\end{tabular}

\subsubsection{Minat Wisatawan Mengunjungi Museum Memorial Jenderal Besar HM. Soeharto}

Koleksi museum Memorial Jenderal Besar HM. Soeharto termasuk lengkap dan modern, dengan berbasis digitalisasi dan komputerisasi yang dapat menjadi sarana dalam edukasi maupun rekreasi pengunjung. Pengunjung. Pengunjung museum berasal dari Yogyakarta maupun luar Yogyakarta. Mereka berasal dari kalangan pelajar, mahasiswa, maupun masyarakat umum. Pelajar pada umumnya datang secara rombongan, mulai dari kelompok TK, SD, SMP, maupun SMA.

Konsep pengenalan koleksi museum berdasarkan tingkatan usia. Misalnya untuk pengunjung kalangan anak-anak disediakan pemutaran film kartun, nyanyian lagu anakanak, dan tempat bermain yang luas. Media tersebut juga diciptakan dengan mengedepankan nilai-nilai sejarah. Selain itu, di dalam kompleks museum juga disediakan kereta mini dengan harga yang terjangkau.

Selain konsep untuk anak-anak, juga konsep disesuaikan untuk kalangan pelajar. Umumnya mereka datang secara rombongan pada saat hari peringatan nasional seperti hari Kartini serta pada saat liburan panjang sekolah. Museum Memorial Jenderal Besar HM. Soeharto tepat dikunjungi kalangan pelajar, karena selain dapat memberikan pembelajaran historis juga dapat menjadi tempat liburan yang nyaman.

Adanya kunjungan berbagai kalangan ke museum Memorial Jenderal Besar HM. Soeharto tentu karena minatnya terhadap keberadaan museum, baik dengan koleksinya maupun suasana lingkungan yang diciptakan di dalam museum. Salah seorang pelajar yang mengunjungi museum menuturkan bahwa tempat tersebut menghadirkan suasana yang nyaman bagi para pengunjung dengan beragam fasilitas, termasuk jaringan internet gratis. Selain itu, museum tersebut juga menyajikan rekam jejak sejarah Jenderal Besar HM. Soeharto serta sejarah perjuangannya untuk bangsa. Pelajar lainnya juga merasa tertarik datang ke Museum Memorial Jenderal Besar HM. Soeharto karena tinggal dekat dengan museum 
tersebut. Selain itu, pengunjung juga datang karena ingin bernostalgia dengan masa kepemimpinan Soeharto. Pengunjung mengakui bahwa pemerintahan era Soeharto tidak sepenuhnya buruk akibat praktik KKN, tetapi juga ada nilai positif tersendiri yang dirasakan masyarakat karena pada masa itu keamanan Indonesia dapat terkendali.

Selain itu, kehidupan Jenderal Besar HM. Soeharto memang menjadi minat salah satu pengunjung yang datang yaitu seorang siswa. la menuturkan bahwa Museum Memorial Jenderal Besar HM. Soeharto menghadirkan kisah hidup HM. Soeharto sebagai sosok yang pernah disegani masyarakat, meskipun beliau juga mengalami isu negatif terkait praktek KKN (Kolusi, Korupsi dan Nepotisme) pada masa pemerintahannya. Keberadaan sumur-sumur yang dipercaya dapat mengabulkan keinginan juga membuat para pengunjung berminat datang ke museum. Selain itu, beragam kegiatan yang diselenggarakan di museum tersebut seperti peringatan RA Kartini juga menjadi daya tarik tersendiri bagi para pengunjung.

Bagi mahasiswa, Museum Memorial Jenderal Besar HM. Soeharto menyajikan teknologi modern, sehingga menimbulkan kesan indah. Beragam fasilitas yang tersedia juga mampu memanjakan pengunjung seperti lahan untuk istirahat yang luas serta wifi. Museum Memorial Jenderal Besar HM. Soeharto juga sering menghadirkan acara bernuansa hari besar nasional. Beragam kegiatan di Museum Memorial Jenderal Besar HM. Soeharto seperti lomba mewarnai dan menggambar bagi anak-anak, kegiataan perayaan hari nasional, kegiatan yang sesuai dengan peristiwa nasional seperti mengadakan pesta rakyat sambil mengenang supersemar, tarawih berjamaah selama bulan ramadhan, dan sebagainya juga menjadi suguhan hiburan sekaligus edukasi bagi masyarakat yang berkunjung. Museum Memorial Jenderal Besar HM. Soeharto juga menyuguhkan sejarah perjuangan para pahlawan yang dapat menjadi sumber materi untuk mendukung referensi para mahasiswa yang mengambil jurusan sejarah, .

Mahasiswa juga memiliki minat terhadap kehidupan pribadi Jenderal Besar HM. Soeharto. Mahasiswa yang tertarik berkunjung ke Museum Memorial Jenderal Besar HM. Soeharto karena ingin mengenal secara lebih mendalam tentang sosok Jenderal Besar HM. Soeharto serta perjuangan beliau semasa menjadi tentara maupun semasa menjabat presiden RI. Selain itu, mahasiswa berminat berkunjung ke Museum Memorial Jenderal
Besar HM. Soeharto karena ingin memanfaatkan fasilitas wifi untuk mengerjakan tugas dan menghabiskan waktu luang di pendopo museum. Mereka biasanya datang bersama temannya dalam kelompok kecil.

Selain mahasiswa, pengunjung dari kalangan masyarakat umum juga memiliki minat terhadap Museum Memorial Jenderal Besar HM. Soeharto. Hal ini dikarenakan adanya sejumlah fasilitas pendukung yang dapat dimanfaatkan masyarakat misalnya pendopo yang dapat difungsikan untuk beragam kegiatan seperti kegiatan lomba, senam dan lain-lain. Museum tersebut juga menjadi media bagi masyarakat yang ingin mengetahui tentang sejarah perjuangan para pahlawan.

Daya tarik lainnya dari Museum Memorial Jenderal Besar HM. Soeharto bagi masyarakat umum diantaranya adalah bagunan yang menarik disertai pendopo yang luas sebagai area publik yang dapat dinikmati pengunjung yang ingin beristirahat dan menghabiskan waktu luang. Masyarakat umum tertarik berkunjung ke Museum Memorial Jenderal Besar HM. Soeharto untuk bernostalgia dengan kepemimpinan beliau yang dianggap baik bagi generasi tua. Ada pula masyarakat yang tertarik berkunjung untuk mengambil air dari sumur petilasan yang dipercaya berkhasiat menyembuhkan berbagai penyakit.

Pengunjung juga berminat mengunjungi Museum Memorial Jenderal Besar HM. Soeharto sebagai tempat rekreasi. Pengunjung dapat memanfaatkan museum sebagai ruang untuk rekreasi dan berkumpul dengan keluarga. Hal ini juga didukung dengan jam buka museum dari pagi sampai sore. Pengunjung dapat menikmati beragam fasilitas yang ada. Pengunjung memiliki minat untuk menjadikan Museum Memorial Jenderal Besar HM. Soeharto sebagai tempat berkumpul dan bersosialisasi sambil menikmati hiburan.

Para pengunjung juga berminat untuk menjadikan Museum Memorial Jenderal Besar HM. Soeharto sebagai tempat rekreasi. Museum Memorial Jenderal Besar HM. Soeharto cocok dijadikan tempat rekreasi karena pengunjung dapat menikmati suasana santai sambil berfoto. Pengunjung, khususnya anak-anak juga dapat menonton film dokumenter Soeharto. Museum Memorial Jenderal Besar HM. Soeharto memang menghadirkan tempat rekreasi yang potensial mendatangkan banyak pengunjung.

Kendati koleksi museum termasuk lengkap dan modern, namun tidak menjamin 
mempertahankan bahkan menaikkan minat pengunjung/wisatawan terhadap Museum Memorial Jenderal Besar HM. Soeharto. Hal ini dilihat dari menurunnya jumlah pengunjung dari tahun 2015-2017. Berdasarkan data dari Buku Statistik Kepariwisataan DI Yogyakarta, jumlah kunjungan pada tahun 2015 sebanyak 250.050 orang, dan menurun pada tahun 2016 sebanyak 206.563. Kunjungan tahun 2017 pun menurun menjadi 183.735 orang.

\subsection{Kesimpulan}

Para pengunjung baik kalangan pelajar, mahasiswa, dan masyarakat umum memiliki minat masing-masing terhadap Museum Memorial Jenderal Besar HM. Soeharto. Pengunjung yang datang juga bervariatif dan umumnya datang secara rombongan yaitu dari kelompok TK, SD, SMP, SMA, Perguruan Tinggi dan masyarakat umum. Pengunjung yang datang ke museum berasal dari Jawa maupun luar Jawa dan mayoritas berasal dari kalangan masyarakat umum. Minat pribadi pelajar yang datang ke Museum Memorial Jenderal Besar HM. Soeharto umumnya adalah untuk melakukan study tour serta mengetahui sejarah kehidupan Jenderal Besar HM. Soeharto, sedangkan minat pribadi mahasiswa adalah untuk mengetahui informasi tentang sejarah kehidupan Jenderal Besar HM. Soeharto serta berkumpul dengan rekanrekan sesama mahasiswa untuk sekedar berdiskusi maupun menikmati fasilitas wifi. Minat pribadi masyarakat umum adalah bernostalgia dan mengenang mendiang Jenderal Besar HM. Soeharto. Pengunjung juga berminat datang ke Museum Memorial Jenderal Besar HM. Soeharto untuk berekreasi dan berkumpul bersama teman dan keluarga sambil memanfaatkan beragam fasilitas yang cukup memadai, koleksi museum yang beragam dan dikemas secara modern, serta adanya unsur historis terkait kehidupan Jenderal Besar HM. Soeharto. Pengunjung juga menunjukkan minat sosial ketika datang ke Museum Memorial Jenderal Besar HM. Soeharto baik sekedar berkumpul dengan keluarga dan teman maupun mengikuti berbagai kegiatan komunitas seperti memperingati hari besar nasional maupun mengikuti kegiatan lomba, senam dan lain-lain.

\section{Daftar Pustaka}

[1] Boniface, P. dan Fowler, P.J. 2011. Heritage and Tourism in the global Village. London: Routledge.

[2] Burkart, A. J dan Medlik, S. 2012. Tourism: Past, Present, and Future. Second Edition. London: Heinemann.

[3] Dean, D. 2013. Museum Exhibition: Theory and Practice. London: Routledge.

[4] Kodhyat, H. 2013. Sejarah Pariwisata dan Perkembangannya di Indonesia. Jakarta: PT Grasindo.

[5] Marpaung, H. 2012. Pengantar Pariwisata. Bandung: Alfabeta.

[6] Maryani, E. 2012. "Pendidikan Geografi", dalam IImu dan Aplikasi Pendidikan. Bandung: Pedagogiana Press.

[7] Sutaarga, M.A. 2012. Museografi dan Museologi. Jakarta: Capita Selecta.

[8] Suwantoro, G. 2011. Dasar-Dasar Pariwisata. Yogyakarta: Andi.

[9] Undang-Undang RI No 10 Tahun 2009 Tentang Kepariwisataan. 